\title{
EPIDEMIOLOGIC ASPECTS OF TRAUMA IN AL-JOUF REGION, SAUDI ARABIA: A RETROSPECTIVE STUDY
}

\author{
DOAA M ABDEL-SALAM ${ }^{1,2 *}$, RAWAN R ALRUWAILI ${ }^{3}$, FARAH S ALHABLANI ${ }^{3}$, NOUR H ALFAHEL ${ }^{3}$, \\ AMAL F ALMUNAHI ${ }^{3}$, ANWAR A ALBLAWI ${ }^{3}$
}

\begin{abstract}
${ }^{1}$ Department of Family and Community Medicine, College of Medicine, Jouf University, Saudi Arabia. ${ }^{2}$ Department of Public Health and Community Medicine, Faculty of Medicine, Assiut University, Egypt. ${ }^{3}$ Medical Student, College of Medicine, Jouf University, Saudi Arabia. Email: dabdelsalam@ju.edu.sa
\end{abstract}

Received: 28 April 2019, Revised and Accepted: 15 July 2019

ABSTRACT

Objectives: This study aimed to determine the types, characteristics, and associated factors of trauma in Al-Jouf Region which is located in Northern part of Saudi Arabia.

Methods: The present study was conducted in the Emergency Department of Prince Meteb Hospital in Al-Jouf Region. A total number of 382 patients were enrolled in the present study. A pre-organized data form were designed for each patient attended the Emergency Department of Prince Meteb Hospital from January 2017 to January 2018. It included data about sociodemographic characteristics, type of trauma, and trauma characteristics.

Results: The mean age of the patients was $24.4 \pm 13.4$ years. Most of the patients $(75 \%)$ were $<30$ years old. Males (86.9\%) were influenced by trauma more common than females. Most of the patients (84.8\%) were from urban areas. Blunt trauma constituted 58.9\% while, penetrating trauma $41.1 \%$. The most common cause of trauma was road traffic accidents, which occurred among $40 \%$ of patients. The most frequent trauma site was head trauma (49\%). Most of the patients (47.9\%) reached the hospital within 30 min. Regarding the fate of patients, $46.1 \%$ discharged after management, $42.1 \%$ admitted to intensive care units, and only $11.8 \%$ died. Blunt trauma was significantly higher than penetrating trauma among the young age group. Patients with blunt trauma arrived hospital significantly earlier than patients with penetrating trauma. The fate of patients is significantly better in blunt trauma than penetrating trauma.

Conclusion: Trauma is considered to be a major public health problem, particularly in the young population in Saudi Arabia. Blunt trauma is more common than penetrating trauma, with road traffic accidents representing the majority.

Keywords: Trauma, Injury, Prevalence, Saudi Arabia.

(C) 2019 The Authors. Published by Innovare Academic Sciences Pvt Ltd. This is an open access article under the CC BY license (http://creativecommons. org/licenses/by/4. 0/) DOI: http://dx.doi.org/10.22159/ajpcr.2019.v12i8.33792

\section{INTRODUCTION}

Trauma is considered to be any physical harm due to violence or other forces [1]. Urgent evaluation, interpretation, and interventions to secure the life of patients and prohibit persistent disability are needed because of these diversity of injuries [2]. Trauma is the main reason of severe morbidities and mortalities within all ages, and its severity varies according to the age group affected with it. The World Health Organization (WHO) has indicated that $12.2 \%$ of the total burden of diseases are due to trauma [3]. The morbidities, mortalities, and disabilities of trauma lead to disproportionate mortalities among children and adults when comparing to other diseases and health problems. These deaths will represent huge load on the health sector and economic sequels for the health care in addition to lack of productivity [4].

Trauma mortalities constitute the tip of the iceberg because of millions of people seeking hospital care for trauma management [5]. Mortality from trauma accounts for most deaths compared with deaths of heart diseases and cancer [6].

Estimation of the WHO said that 16,000 people die every day from injuries and trauma, and for everyone who dies, several thousand more are injured, many of them with permanent consequences [7]. Assistance for and international recognition of injury control efforts are below the levels given to other health problems, especially in the developing world [8,9]. With the advent of 2020, 8.4 million people will die every year from trauma, and trauma due to road traffic accidents will be the third most prevalent reason of disability worldwide and the second most prevalent reason in the developing countries [10]. In Saudi Arabia, the leading cause of hospitalization was trauma, one person is killed and four are injured every hour due to traumatic reasons [11].

Injuries are categorized as unintentional and intentional. Unintentional injury involves injuries due to traffic, occupational trauma, falls, and drowning. The intentional injury involves interpersonal homicide and violence [12]. Road traffic accidents (RTAs) constitute 80\%-85\% of the traumas in Saudi Arabia; almost these victims need long-term rehabilitation care due to residual disabilities [13]. Domestic accidents are considered of public health concern. Cuts are considered to be the most accident type, then burn and falls [14]. Natural disaster injuries are increasing disproportionally [15]. In Saudi Arabia, data relevant to human losses due to disasters that happened between 1980 and 2010 showed that the number of dead persons was 484 , while the number of traumatized persons was 29203; most of them were because of floods [16]. There was obvious decrease of occupational injuries in the developed world while it is still high in the developing world [17].

Traumatic deaths due to firearm injury did not confine to any area. Nearly 22 million people have been killed since 1945 and 3 times as many traumatized during war or violent accident [18].

To the best of authors' knowledge, no published study had been conducted to determine epidemiological aspects of trauma in Al-Jouf Region, Saudi Arabia. Since previous studies had reported higher rates 
of trauma in Saudi Arabia [5,9,11]. Therefore, the present study was implemented with the aim of understanding the types, characteristics, and associated factors of trauma in Al-Jouf Region which is located in the Northern part of Saudi Arabia.

\section{METHODS}

\section{Study design}

A retrospective study was adopted to review hospital records of all traumatized patients presented to the Emergency Department of Prince Meteb Hospital in Al-Jouf Region, Saudi Arabia between January 2017 and January 2018 and whose records were complete and available. The researchers utilized a special data form to gather the required information. Collection of data was done through the academic year $2017 / 2018$.

\section{Setting}

The present study was done at the Emergency Department of Prince Meteb Hospital, Al-Jouf region, Saudi Arabia. Prince Meteb Hospital is considered the central referral hospital in Al-Jouf Region.

\section{Inclusion criterion}

The records of all patients with various types of trauma were included in the study.

\section{Exclusion criteria}

The records of all patients with burns, electrocution, or poisoning were excluded from the study.

\section{Data collection tool}

The data were obtained from the database office at the Emergency Department of Prince Meteb Hospital. A special data form were utilized to gather data regarding sociodemographic characteristics, type of trauma, and trauma characteristics. Sociodemographic characteristics included age, sex, nationality, residence, occupation, marital status, and educational level. Types of trauma in the present study were blunt and penetrating. RTAs, falling down and violence were considered to be blunt trauma. Stabbing and firearm injury was considered to be penetrating trauma. The present study also inquired about trauma characteristics such as site of trauma, time of hospital arrival, and fate of patients after trauma.

\section{Statistical procedure}

Data analysis was performed using SPSS program version 21 for statistical analysis. Descriptive statistics were applied (frequencies and percentages), and Chi-square was utilized for comparing qualitative data. $\mathrm{p} \leq 0.05$ was considered to be statistically significant.

\section{RESULTS}

The sociodemographic features of the patients are depicted in Table 1. About $72 \%$ of patients were less than 30 years old with the mean age 24.4 \pm 13.4 . Most of the patients were males (86.9\%) and Saudi $(80.6 \%)$. Furthermore, most of them were single $(36.1 \%)$ and under age of marriage (31.2\%). About $28 \%$ of them are not working and employees represent $40.6 \%$. Nearly $85 \%$ live in urban areas. Regarding the educational level, most of them $(42.9 \%)$ had to get a university education or above.

The types of trauma among the patients are presented in Fig. 1. Nearly $59 \%$ were blunt trauma, while $41.1 \%$ were penetrating trauma. Table 2 showed the characteristics of trauma among patients. RTAs were the predominant reason for trauma $(40 \%)$ followed by stabbing (28\%). Head trauma was seen among $49 \%$ of patients followed by upper limb trauma (33.5\%) and chest trauma (24.3\%). Most of the patients $(47.9 \%)$ reached the hospital within 30 min after the trauma. Regarding the fate of patient after trauma, $46.1 \%$ were discharged after management, $42.1 \%$ admitted to intensive care units and only $11.8 \%$ died. Relationship between type of trauma and sociodemographic characteristics is presented in Table 3. The blunt trauma was
Table 1: Sociodemographic data of traumatized patients in Al-Jouf Region, Saudi Arabia

\begin{tabular}{|c|c|c|}
\hline $\begin{array}{l}\text { Sociodemographic } \\
\text { variables }\end{array}$ & No. (382) & $\%$ \\
\hline \multicolumn{3}{|l|}{ Age: years } \\
\hline$<20$ & 143 & 37.4 \\
\hline $20-30$ & 134 & 35.1 \\
\hline$>30$ & 105 & 27.5 \\
\hline Mean \pm SD; Median (Range) & \multicolumn{2}{|c|}{$24.43 \pm 13.37 ; 22.0(1.0-96.0)$} \\
\hline Male & 332 & 86.9 \\
\hline Female & 50 & 13.1 \\
\hline \multicolumn{3}{|l|}{ Nationality } \\
\hline Saudi & 308 & 80.6 \\
\hline Others & 74 & 19.4 \\
\hline \multicolumn{3}{|l|}{ Marital status } \\
\hline Under age of marriage & 119 & 31.2 \\
\hline Single & 138 & 36.1 \\
\hline Married & 125 & 32.7 \\
\hline \multicolumn{3}{|l|}{ Occupation } \\
\hline Under age of work & 119 & 31.1 \\
\hline Employee & 155 & 40.6 \\
\hline Not working & 108 & 28.3 \\
\hline \multicolumn{3}{|l|}{ Residence } \\
\hline Rural & 58 & 15.2 \\
\hline Urban & 324 & 84.8 \\
\hline \multicolumn{3}{|l|}{ Educational level } \\
\hline Under age & 25 & 6.5 \\
\hline Illiterate & 60 & 15.7 \\
\hline Primary & 10 & 2.6 \\
\hline Preparatory & 25 & 6.5 \\
\hline Secondary & 98 & 25.7 \\
\hline University & 72 & 18.8 \\
\hline Postgraduate & 92 & 24.1 \\
\hline
\end{tabular}

Table 2: Trauma characteristics in Al-Jouf Region, Saudi Arabia

\begin{tabular}{lll}
\hline Trauma characteristics & No. (382) & \% \\
\hline Cause of trauma & & \\
Road traffic accident & 153 & 40.0 \\
Stabbing & 107 & 28.0 \\
Fire arm injury & 50 & 13.1 \\
Falling down & 42 & 11.0 \\
Violence & 30 & 7.9 \\
Site of trauma* & & \\
Head trauma & 187 & 49.0 \\
Upper limb trauma & 128 & 33.5 \\
Chest trauma & 93 & 24.3 \\
Lower limb trauma & 73 & 19.1 \\
Abdominal trauma & 34 & 8.9 \\
Back trauma & 33 & 8.6 \\
Pelvic trauma & 24 & 6.3 \\
Interval between trauma and hospitalization & & \\
<30 min & 183 & 47.9 \\
30-60 min & 119 & 31.2 \\
>60 min & 80 & 20.9 \\
Fate of patient & & \\
Discharged & 176 & 46.1 \\
Admitted to intensive care units & 161 & 42.1 \\
Died & 45 & 11.8 \\
\hline
\end{tabular}

*More than one answer had been reported

significantly more frequent among patients $<20$ years old as $52.4 \%$ of patients with blunt trauma were $<20$ years old compared to $15.9 \%$ of patients with penetrating trauma $(\mathrm{p}=0.000)$. However, no significant differences were found between the type of trauma on the one hand and other sociodemographic characteristics such as gender, nationality, marital status, residence, occupation, and educational level, on the other hand. Table 4 showed that patients with blunt trauma reached the hospital faster than those with penetrating trauma $(p=0.000)$. Nearly 


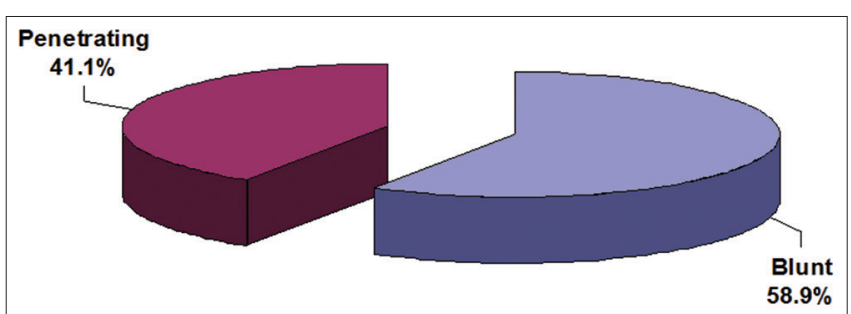

Fig. 1: Types of trauma among patients attended the Emergency Department of Prince Meteb Hospital in Al-Jouf Region, Saudi Arabia

Table 3: Relationship between type of trauma and sociodemographic data in Al-Jouf Region, Saudi Arabia

\begin{tabular}{|c|c|c|c|c|c|}
\hline \multirow{3}{*}{$\begin{array}{l}\text { Sociodemographic } \\
\text { variables }\end{array}$} & \multicolumn{4}{|c|}{ Type of trauma } & \multirow[t]{3}{*}{ p-value } \\
\hline & \multicolumn{2}{|c|}{ Blunt $(n=225)$} & \multicolumn{2}{|c|}{$\begin{array}{l}\text { Penetrating } \\
(n=157)\end{array}$} & \\
\hline & $\mathbf{n}$ & $\%$ & $\mathbf{n}$ & $\%$ & \\
\hline Age: years & & & & & $0.000^{*}$ \\
\hline$<20$ & 118 & 52.4 & 25 & 15.9 & \\
\hline $20-30$ & 75 & 33.3 & 59 & 37.6 & \\
\hline$>30$ & 32 & 14.2 & 73 & 46.5 & \\
\hline Gender & & & & & 0.161 \\
\hline Male & 191 & 84.9 & 141 & 89.8 & \\
\hline Female & 34 & 15.1 & 16 & 10.2 & \\
\hline Nationality & & & & & 0.345 \\
\hline Saudi & 185 & 82.2 & 123 & 78.3 & \\
\hline Others & 40 & 17.8 & 34 & 21.7 & \\
\hline Marital status & & & & & 0.253 \\
\hline $\begin{array}{l}\text { Under age of } \\
\text { marriage }\end{array}$ & 77 & 34.2 & 42 & 26.8 & \\
\hline Single & 80 & 35.6 & 58 & 36.9 & \\
\hline Married & 68 & 30.2 & 57 & 36.3 & \\
\hline Occupation & & & & & 0.286 \\
\hline $\begin{array}{l}\text { Under the age of } \\
\text { work }\end{array}$ & 77 & 34.2 & 42 & 26.8 & \\
\hline Employee & 86 & 38.2 & 69 & 43.9 & \\
\hline Not working & 62 & 27.6 & 46 & 29.3 & \\
\hline Residence & & & & & 0.228 \\
\hline Rural & 30 & 13.3 & 28 & 17.8 & \\
\hline Urban & 195 & 86.7 & 129 & 82.2 & \\
\hline Educational level & & & & & 0.191 \\
\hline Under age & 17 & 7.6 & 8 & 5.1 & \\
\hline Illiterate & 43 & 19.1 & 17 & 10.8 & \\
\hline Basic education & 17 & 7.6 & 18 & 11.5 & \\
\hline Secondary & 55 & 24.4 & 43 & 27.4 & \\
\hline University & 39 & 17.3 & 33 & 21.0 & \\
\hline Postgraduate & 54 & 24.0 & 38 & 24.2 & \\
\hline
\end{tabular}

$\mathrm{p}$ value was calculated using the Chi-square test. ${ }^{*}$ Significant at $\mathrm{p}<0.05$
$55 \%$ of patients with blunt trauma reached the hospital within $30 \mathrm{~min}$ compared to $37.6 \%$ of patients with penetrating trauma. Regarding fate after trauma, most patients with blunt trauma (54.2\%) were discharged after management compared to $34.4 \%$ of patients with penetrating trauma. However, $26.1 \%$ of patients with penetrating trauma were died compared to $1.8 \%$ of patients with blunt trauma $(\mathrm{p}=0.000)$.

\section{DISCUSSION}

Trauma is considered to be one of the most common causes of permanent disability and death. It happens more frequent among people at the age of 15-40 years causing a fatality rate of $10 \%$. For every trauma death, several patients are left with permanent disability and constitute a major economic burden for society [19].

The present study aimed to demonstrate the types, characteristics, and associated factors of trauma in Al-Jouf Region, Saudi Arabia. Socio-demographic characters of patients revealed that most of the victims were young people. Unlike chronic diseases that happen late in life, trauma has its effect on young and middle-aged people [20]. The present study showed that males are more likely to have trauma than females. This is because males are more prone to be engaged in road traffic accidents and violent activities, as well as stress due to work. This is in agreement with the Egyptian injury surveillance report [21] and with other studies done in Pakistan, Iran, and Uganda [22-24]. The present study showed that most patients were from urban regions. The urban expansion and great civilization in Saudi Arabia accompanying oil discovery, and the huge increase in living standards have participated in increasing the number RTAs [25].

In the present study, blunt trauma was more prevalent than penetrating trauma and RTAs was the most common reason for injury in patients with blunt trauma. The WHO showed that the mortality rate in Saudi Arabia due to RTAs was 24.8 per 100,000 population (more than 130,000 deaths every year). The mortality rate due to RTAs differs among Gulf countries. It was 10.5 per 100,000 population in Bahrain, 16.5 in Kuwait, 12.7 in UAE, and 30.4 in Oman. These studies revealed that noncompliance with traffic guidelines and dangerous driving habits was the causes of these mortalities [26].

Rapid transfer to the hospital is very urgent and important issue [27]. In the present study, most patients reached the hospital within $30 \mathrm{~min}$ after trauma. The transport duration differed greatly among studies from 20 to $30 \mathrm{~min}$ [6] up to $50 \mathrm{~min}$ [27].

The present study showed that $46.1 \%$ of patients were discharged home after management, $42.1 \%$ admitted to the intensive care unit and $11.8 \%$ died. Kazmi et al. showed that the majority of traumatized patients (69\%) were discharged after management, $20 \%$ transported to the wards of their hospital or other hospitals and $11 \%$ died [28]. Hokkam et al. showed that $48.2 \%$ of patients discharged home, $17 \%$ transferred

Table 4: Relationship between type of trauma and trauma characteristics in Al-Jouf Region, Saudi Arabia

\begin{tabular}{|c|c|c|c|c|c|}
\hline & \multicolumn{4}{|c|}{ Type of trauma } & \multirow[t]{3}{*}{ p-value } \\
\hline & \multicolumn{2}{|c|}{ Blunt (n=225) } & \multicolumn{2}{|c|}{ Penetrating ( $n=157)$} & \\
\hline & $\mathbf{n}$ & $\%$ & $\mathbf{n}$ & $\%$ & \\
\hline Interval between trauma and hospitalization & & & & & $0.000^{*}$ \\
\hline$<30 \min$ & 124 & 55.1 & 59 & 37.6 & \\
\hline $30-60 \mathrm{~min}$ & 72 & 32.0 & 47 & 29.9 & \\
\hline$>60 \mathrm{~min}$ & 29 & 12.9 & 51 & 32.5 & \\
\hline Fate of patient & & & & & $0.000^{*}$ \\
\hline Discharged & 122 & 54.2 & 54 & 34.4 & \\
\hline Admitted to ICU & 99 & 44.0 & 62 & 39.5 & \\
\hline Died & 4 & 1.8 & 41 & 26.1 & \\
\hline
\end{tabular}

$\mathrm{p}$ value was calculated using the Chi-square test. ${ }^{*}$ Significant at $P<0.05$ 
to the operation room, and only $2.6 \%$ died [5]. The variability between different studies may be due to the disparities between the equipment and facilities used in the hospitals. This study showed that blunt trauma is significantly higher than penetrating trauma in the young age group $<20$ years. The more freedom and outdoor life encountered in a young age are an important cause of such trauma. Studies done in Pakistan and Iran $[22,23]$ demonstrated that trauma is high in the younger ages, which are the most productive age groups of society indicating great economic loss to the country. The present study showed that most patients with blunt trauma reached hospital earlier than patients with penetrating trauma. This is because most blunt trauma in this study were road traffic accidents which occurred in the street with the arrival of the ambulance at the site of the accident and quick transportation by trained personnel. This quick transportation may improve the outcome of the victims, and this was noticed in the present study which showed that most patients with blunt trauma discharged home after management and had less mortality than patients with penetrating trauma.

\section{CONCLUSION}

The high prevalence of road traffic accidents in Al-Jouf Region, Saudi Arabia should give a warning sign to public health authorities. Successful prevention will be achieved through an integrated approach to traffic safety that focuses on vehicles, road users, and road infrastructure in addition to traffic safety education and effective enforcement.

\section{ACKNOWLEDGMENT}

The authors would like to acknowledge administrators of the hospital for assisting in the administrative aspects for the conduction of the present study. Extreme thanks to Dr. Abdulrahman Al Maeen, Dean of College of Medicine, Jouf University, Saudi Arabia, for his grateful encouragement in doing this research work.

\section{AUTHORS' CONTRIBUTIONS}

This study was conducted by DM, RR, FS, NH, AF, and AA, suggesting the title of the manuscript, data collection, and data entry were done by RR, FS, NH, AF, and AA. Data analysis, interpretation, and manuscript preparation were performed by DM. All authors read and approved the final draft of the manuscript.

\section{CONFLICTS OF INTEREST}

Authors declare that there are no conflicts of interest.

\section{FUNDING}

The present study was not supported by any National or International Institution or Organization.

\section{ETHICAL APPROVAL AND CONSENT TO PARTICIPATE}

The study was done with the approval of the Ethics Review Committee of Jouf University, Saudi Arabia. Administrators of the hospital were informed about the study and its objectives. Privacy and confidentiality of all information were assured.

\section{REFERENCES}

1. Baker SP. Where have you been and where are you going with injury control? In: Mohan D, Tiwari G, editors. Injury Prevention and Control. New York: Taylor and Francis Publisher; 2000.

2. Tabish SA, Shah S, Bhat AS, Bhat FA, Shoukat H, Mir MY. Clinical profile and mortality pattern in patients of ballistic trauma. J Int Med Sci Acad 2004;13:247-50.

3. World Health Organization. Global Burden of Disease. Geneva, Switzerland: World Health Organization; 2004. Available from: http://www.who.int/healthinfo/global_burden_disease/GBD_ report_2004update_full.pdf.
4. World Health Organization. Disability in the South East Asia Region. Regional Office for South East Asia, New Delhi: World Health Organization; 2013. Available from: http://www.searo.who.int/ entity/disabilities injury rehabilitation/topics/disabilityinsear2013. pdf?ua $=1$.

5. Hokkam E, Gonna A, Zakaria O, El-Shemally A. Trauma patterns in patients attending the emergency department of Jazan general hospital, Saudi Arabia. World J Emerg Med 2015;6:48-53.

6. Ali K, Arain GM, Masood AS, Aslam M. Pattern of injuries in trauma patients presenting in accident and emergency department of Jinnah hospital, Lahore. Ann King Edward Med Coll 2006;12:26.

7. World Health Organization. World Report on Violence and Health. Geneva, Switzerland: World Health Organization; 2002. Available from: http://www.who.int/violence_injury_prevention/violence/world_ report/en/summary_en.pdf.

8. Zwi AB, Forjuoh S, Murugusampillay S, Odero W, Watts C. Injuries in developing countries: Policy response needed now. Trans R Soc Trop Med Hyg 1996;90:593-5.

9. Hofman K, Primack A, Keusch G, Hrynkow S. Addressing the growing burden of trauma and injury in low and middle-income countries. Am J Public Health 2005;95:13-7.

10. Murray CJ, Lopez AD. Alternative projections of mortality and disability by cause 1990-2020: Global burden of disease study. Lancet 1997;349:1498-504.

11. Ansari S, Akhdar F, Mandoorah M, Moutaery K. Causes and effects of road traffic accidents in Saudi Arabia. Public Health 2000;114:37-9.

12. World Health Organization. Injuries and Violence: The Facts. Geneva, Switzerland: World Health Organization; 2010. Available from: http:// www.who.int/violence_injury_prevention/key_facts/en.

13. Al-Turki S. Trauma and ATLS training in Saudi Arabia. Middle East J Emerg Med 2001;1:50-5.

14. Bhanderi DJ, Choudhary S. A study of occurrence of domestic accidents in semi-urban community. Indian J Community Med 2008;33:104-6.

15. Smith K. Environmental Hazards. $2^{\text {nd }}$ ed. London, New York: Routledge; 1996.

16. UNISDR: Prevention Web Saudi Arabia Disaster Statistics. Available from: http://www.preventionweb.net/english/countries/ statistics $/$ ?cid $=150$.

17. Drever F. Occupational Health Decennial Supplement. $1^{\text {st }}$ ed. London: HMSO; 1995.

18. Summerfield D. The social, cultural and political dimensions of contemporary war. Med Confl Surviv 1997;13:3-25.

19. Mizelle HL, Rothrock SG, Silvestri S, Pagane J. Preventable morbidity and mortality from prehospital paralytic assisted intubation: Can we expect outcomes comparable to hospital-based practice? Prehosp Emerg Care 2002;6:472-5.

20. Morris SC. The team approach to management of the polytrauma patient. Virtual Mentor 2009;11:516-20.

21. World Health Organization. Injury Surveillance, a Tool for Decisionmaking: Annual Injury Surveillance Report, Egypt. Regional Office for the Eastern Mediterranean, Arab Republic of Egypt, Ministry of Health: World Health Organization; 2009. Available from: http://www. applications.emro.who.int/dsaf/dsa1087.pdf.

22. Ahmed M, Shah M, Luby S, Drago-Johnson P, Wali S. Survey of surgical emergencies in a rural population in the northern areas of Pakistan. Trop Med Int Health 1999;4:846-57.

23. Norouzi V, Feizi I, Vatankhah S, Pourshaikhian M. Calculation of the probability of survival for trauma patients based on trauma score and the injury severity score model in Fatemi hospital in Ardabil. Arch Trauma Res 2013;2:30-5.

24. Kobusingye OC, Guwatudde D, Owor G, Lett RR. Citywide trauma experience in Kampala, Uganda: A call for intervention. Inj Prev 2002;8:133-6.

25. Al-Naami MY, Arafah MA, Al-Ibrahim FS. Trauma care systems in Saudi Arabia: An agenda for action. Ann Saudi Med 2010;30:50-8.

26. World Health Organization. Global Status Report on Road Safety. Geneva, Switzerland: World Health Organization; 2015. Available from: http://www.who.int/violence injury prevention/road safety status/2015/en.

27. Vajda P. Prehospital care of the adult trauma patient. Bratisl Lek Listy 2007;108:371-4.

28. Kazmi TH, Omair A, Inam SN, Shaikh I, Jamali S. Spectrum of injuries at the emergency department of a tertiary care hospital. J Coll Physicians Surg Pak 2004;14:61. 